\title{
GRUPO DE CUIDADOS PALIATIVOS EM PEDIATRIA: MULTIDISCIPLINARIDADE A SERVIÇO DO CUIDADO DE EXCELÊNCIA
}

Pôster

Autores deste trabalho:

Denise Madureira: Hospital Infantil Sabará

Maíra Lilian Recchia Santa Cruz: Hospital Infantil Sabará

Thaís Oliveira Franco: Hospital Infantil Sabará

Thaís Sanglard de Souza Reche: Hospital Infantil Sabará

Área do Trabalho: Pediatria

ata da submissão: 09/08/2018 às 15:29

Justificativa

Cuidado paliativo pediátrico é definido como "assistência ativa e total do corpo, mente e espírito da criança, e a prestação de apoio à família, inclusive no período do luto" (1). O momento da finitude da criança em cuidados paliativos, frequentemente acontece no ambiente hospitalar e a equipe, anteriormente dedicada a cura da enfermidade, depara- se, então, com a terminalidade e com a dor da família (2-3).

\section{Objetivo(s)}

Descrever a experiência da implantação de um grupo de cuidados paliativos interdisciplinar em um hospital pediátrico da rede privada.

\section{Método(s)}

Trata-se de um relato de experiência com ênfase na dinâmica de trabalho adotada pelo grupo de cuidados paliativos e seus desdobramentos na assistência ao paciente e seus familiares.

\section{Resultado(s)}

Foram realizados 28 encontros desde a implantação do grupo de cuidados paliativos até o momento com periodicidade semanal. Os temas discutidos englobaram a discussão e programação terapêutica dos pacientes em acompanhamento, formulação de protocolos e temas do escopo específico. O grupo é multiprofissional composto por membros da equipe médica, enfermagem, psicologia, fisioterapia, fonoaudiologia e nutrição. O fluxograma de atendimento de pacientes tem início com a equipe de médicos intensivistas e enfermeiros cujo envolvimento favorece a sensibilização e conscientização dos familiares quanto a necessidade dos cuidados do grupo. A média de pacientes atendidos semanalmente varia de 3 a 5 e as patologias são variadas.

\section{Conclusão (ões)}

A implantação de um grupo de cuidados paliativos multidisciplinar tem gerado importantes mudanças na forma de encarar e tratar as crianças e suas famílias frente a doenças crônicas e de prognóstico reservado. As repercussões dos cuidados prestados têm concorrido para a realização de projetos dentro da instituição como "a 
$4^{\circ}$ Congresso

Internacional

Sabará

13 a 15 de

setembro de 2018

Hotel Maksoud Plaza
Aameda Campinas, 150
Săo Paulo - Brasil

realização de sonhos" das crianças em cuidados paliativos e a estruturação de um aplicativo para a formalização e padronização de protocolo institucional. 